\title{
PLUTONIUM-URANIUM SEPARATION IN THE PUREX PROCESS USING MIXTURES OF HYDROXYLAMINE NITRATE AND FERROUS SULFAMATE
}

by

J. Malvyn McKibben David F. Chostner Errol G. Orebaugh

\section{DISCLAIMER}

\begin{abstract}
This report was prepared as an account of work sponsored by an agency of the United States Government. Neither the United States Government nor any agency thereof, nor any of their employees, makes any warranty, express or implied, or assumes any legal liability or responsibility for the accuracy, completeness, or usefulness of any information, apparatus, product, or process disclosed, or represents that its use would not infringe privately owned rights. Reference herein to any specific commercial product, process, or service by trade name, trademark, manufacturer, or otherwise does not necessarily constitute or imply its endorsement, recommendation, or favoring by the United States Government or any agency thereof. The views and opinions of authors expressed herein do not necessarily state or reflect those of the United States Government or any agency thereof.
\end{abstract}

Publication Date: November 1983

\section{E. I. du Pont de Nemours \& Co. Savannah River Laboratory Aiken, SC 29808}

PREPARED FOR THE U. S. DEPARTMENT OF ENERGY UNDER CONTRACT DE-AC09-76SRO0001

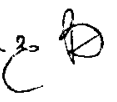




\section{DISCLAIMER}

This report was prepared as an account of work sponsored by an agency of the United States Government. Neither the United States Government nor any agency Thereof, nor any of their employees, makes any warranty, express or implied, or assumes any legal liability or responsibility for the accuracy, completeness, or usefulness of any information, apparatus, product, or process disclosed, or represents that its use would not infringe privately owned rights. Reference herein to any specific commercial product, process, or service by trade name, trademark, manufacturer, or otherwise does not necessarily constitute or imply its endorsement, recommendation, or favoring by the United States Government or any agency thereof. The views and opinions of authors expressed herein do not necessarily state or reflect those of the United States Government or any agency thereof. 


\section{DISCLAIMER}

Portions of this document may be illegible in electronic image products. Images are produced from the best available original document. 
Laboratory studies, followed by plant operation, established that a mixture of hydroxylamine nitrate (HAN) and ferrous sulfamate (FS) is superior to FS used alone as a reductant for plutonium in the Purex first cycle. FS usage has been reduced by about $70 \%$ (from 0.12 to $0.04 \mathrm{M}$ ) compared to the pre-1978 period. This reduced the volume of neutralized waste due to FS by 194 1iters/metric ton of uranium (MTU) processed. The new flowsheet also gives lower plutonium losses to waste and at least comparable fission product decontamination. To achieve satisfactory performance at this low concentration of $\mathrm{FS}$, the acidity in the $1 \mathrm{~B}$ mixer-settler was reduced by using a "split-scrub" - a low acid scrub in stage one and a higher acid scrub in stage three - to remove acid from the solvent exiting the $1 \mathrm{~A}$ centrifugal contactor. 


$\begin{array}{lc}\text { Introduction } & \frac{\text { Page }}{\text { Discussion }} \\ \text { Flowsheet } & 5 \\ \text { Reductant Chemistry } & 5 \\ \text { Laboratory Data } & 7 \\ \text { Plant Tests Without Split-Scrub } & 9 \\ \text { Split-Scrub Flowsheet Development } & 10 \\ \text { Plant Tests With Split-Scrub } & 11 \\ \text { References } & 13 \\ \text { Table } 1 & 14 \\ \text { Figures 1-14 } & 15-28\end{array}$




$$
\text { . }
$$


PLUTONIUM-URANIUM SEPARATION IN THE PUREX PROCESS USING MIXTURES OF HYDROXYLAMINE NITRATE AND FERROUS SULFAMATE

\section{INTRODUCTION}

In all Purex processes the plutonium is reduced to $\mathrm{Pu}$ (III) at the point in the process where plutonium is separated from uranium. The reductant used at the Savannah River Plant from 1954 to 1978 was ferrous sulfamate (FS). The principal advantage of $F S$ is that it gives very rapid reduction of $\mathrm{Pu}(\mathrm{IV})$ to $\mathrm{Pu}$ (III) even in moderately strong nitric acid. "However, FS has a major disadvantage; it is consumed in the large mixer-settler of the Purex first cycle greatly in excess of its stoichiometric requirement and adds considerably to the volume of waste.

In the Purex second plutionium cycle, laboratory and plant testing completed in 1970 led to the use of hydroxylamine nitrate (HAN) as a replacement for hydroxylamine sulfate for plutonium reduction. This work indicated that HAN might also have application in the first solvent extraction cycle where the plutonium-uranium separation takes place (1). HAN is a desirable reductant because when fed to the evaporator in normal waste processing, it oxidizes to gases and contributes no salts to waste. Since little information was available on its properties, laboratory and plant studies were made to determine if HAN could be used in the first cycle to reduce the required amount of ferrous sulfamate.

\section{DISCUSSION}

\section{Flowsheet}

The overall SKP Purex flowsheet is shown in a simplified schematic in Figure 1. A solution of dissolved irradiated targets of depleted uranium is clarified and then processed through solvent extraction. The first solvent extraction cycle cleanly" separates uranium from plutonium and provides the initial decontamination from fission products. The partially purified aqueous streams of plutonium and uranium coming out of the first cycle are each processed through one additional solvent extraction cycle for further fission product decontamination.

Two types of solvent extraction equipment are used. The first "bank" (1A) consists of eighteen centrifugal contactors; all others are mixer-settlers that use gravity for the phase separation. The centrifugal contactors were designed at $\mathrm{SRL}^{(2)}$ and were installed in the plant in $1966^{(3)}$. The principal advantage of centrifugal contactors is that they give much less solvent radiation exposure than other types of solvent extraction equipment. Figure 2 shows in more detail the single-scrub flowsheet used in the Purex first cycle from 1954-1981. 
First cycle feed ( $1 \mathrm{AF}$ ) containing uranium, plutonium, and fission products enters stage 10 of the $1 \mathrm{~A}$ centrifugal contactor ( $1 A C(C)$. Plutonium, uranium, and some $\mathrm{HNO}_{3}$ are extracted into the lAX solvent ( 30 vol \% tributyl phosphate in n-paraffin diluent). The solvent is scrubbed with $3 \mathrm{M} \mathrm{HNO}_{3}$ (1AS stream) to remove fission products before leaving the lACC enroute to the $1 \mathrm{~B}$ mixer-settler. Fission products exit the $1 \mathrm{ACC}$ in the aqueous waste stream ( $1 \mathrm{AW}$ ).

The lAP solvent stream containing uranium and plutonium is fed to stage 11 of the $1 \mathrm{~B}$ mixer-settler. The reductant in the $1 \mathrm{BX}$ stream reduces $\mathrm{Pu}(\mathrm{IV})$ to the inextractable $\mathrm{Pu}(\mathrm{III})$. The aqueous phase can then strip plutonium from the solvent, thereby effecting a partitioning of plutonium from uranium. The aqueous plutonium stream is scrubbed with solvent (1BS) to remove traces of uranium. Typically the plutonium in the 1BP stream contains less than $50 \mathrm{ppm}$ uranium and the uranium in the $1 \mathrm{BU}$ stream contains less than $10 \mathrm{ppb}$ plutonium. FS alone at about $0.12 \mathrm{M}$ to $0.14 \mathrm{M}$ (depending on the $\mathrm{Pu}$ concentration) was used as the reductant from 1954-1977, but a mixed reductant of FS and HAN has been used since 1978 .

\section{Reductant Chemistry}

As stated previously, ferrous ion rapidly reduces plutonium from plutonium (IV) to the inextractable plutonium (III).

$$
\mathrm{Fe}^{+2}+\mathrm{Pu}^{+4} \text { (solvent) } \longrightarrow \mathrm{Pu}^{+3} \text { (aqueous) }+\mathrm{Fe}^{+3}
$$

Sulfamate acts as a "holding reductant" by rapidly destroying nitrite which is radiolytically generated from nitrate.

$$
\mathrm{NH}_{2} \mathrm{SO}_{3}^{-1}+\mathrm{NO}_{2}^{-} \longrightarrow \mathrm{N}_{2}+\mathrm{SO}_{4}^{-2}+\mathrm{H}_{2} \mathrm{O}
$$

This minimizes (but does not eliminate) unwanted oxidation of iron (II) and plutonium (III).

$$
\begin{aligned}
& \mathrm{Fe}^{+2}+\mathrm{NO}_{2}^{-}+2 \mathrm{H}^{+} \longrightarrow \mathrm{Fe}^{+3}+\mathrm{NO}+\mathrm{H}_{2} \mathrm{O} \\
& \mathrm{Pu}^{+3}+\mathrm{NO}_{2}^{-}+2 \mathrm{H}^{+} \longrightarrow \mathrm{Pu}^{+4}+\mathrm{NO}+\mathrm{H}_{2} \mathrm{O}
\end{aligned}
$$

This system works well except that the concentration of FS in the $1 B X$ stream required to maintain plutonium (III) throughout SRP's large $1 \mathrm{~B}$ mixer-settler was 0.12 to $0.14 \mathrm{M}$ depending on the plutonium concentration. This is far in excess of the stoichiometic amount. Excess consumption has been observed in all Purex operations, but is influenced by holdup time and volume. SRP's large mixer-settlers 
particularly aggravate the problem. Since all of the FS added ends up as ferric and sulfate salts in waste, the FS (when used alone) was responsible for about 290 to 340 liters of neutralized waste concentrate per metric ton of uranium processed.

HAN was adopted as the plutonium reductant in the Purex second cycle during the early $1970^{\prime} \mathrm{s}(1)$. Based on this experience, an investigation was started to determine HAN's suitability for the uranium-plutonium partitioning in the higher acid first cycle. HAN had been shown to reduce not only plutonium (IV), but also iron (III).

$$
\begin{aligned}
& 2 \mathrm{NH}_{3} \mathrm{OH}^{+}+4 \mathrm{Pu}^{+4} \longrightarrow 4 \mathrm{Pu}^{+3}+\mathrm{H}_{2} \mathrm{O}+\mathrm{N}_{2} \mathrm{O}+6 \mathrm{H}^{+} \\
& 2 \mathrm{NH}_{3} \mathrm{OH}^{+}+4 \mathrm{Fe}^{+3} \longrightarrow 4 \mathrm{Fe}^{+2}+\mathrm{H}_{2} \mathrm{O}+\mathrm{N}_{2} \mathrm{O}+6 \mathrm{H}^{+}
\end{aligned}
$$

These reactions are slower than 1) and 2), but they are much faster at lower acidity. $(1,4)$ (It also destroys nitrite, but the reaction is slower at lower acidity.(5)) This suggested it might be possible to use a mixture of FS-HAN, with much lower FS concentration, instead of FS alone in the first cycle.

\section{Laboratory Data}

Laboratory experiments were conducted to:

- Determine the rate of plutonium reduction by HAN as a function of nitric acid concentration.

- Evaluate the effect of iron on plutonium reduction by HAN at high nitric acid concentrations.

- Verify HAN stability at the temperature and acidity to be used in the first cycle.

- Determine minimum concentrations of nitric acid (without nitrous acid present) needed to produce rapid and safe decomposition of HAN during waste evaporation.

- Establish the minimum concentration of nitrous acid (with varying nitric acid) needed to decompose HAN so that plutonium can be adjusted to $\mathrm{Pu}$ (IV) in the feed preparation step for the second plutonium solvent extraction cycle.

Earlier work(1) established that the rate of $\mathrm{Pu}(\mathrm{IV})$ reduction by HAN decreases sharply with increasing nitric acid concentrations, as shown in Figure 3. Barney (4) subsequently studied this reaction, and showed the rate to be an inverse function of the fourth power of the hydrogen ion concentration:

$$
\frac{-d[\mathrm{Pu}(\mathrm{IV})]}{d t}=\frac{\mathrm{K}^{\prime}\left[\mathrm{Pu}(\mathrm{IV}]^{2}\left[\mathrm{NH}_{3} \mathrm{OH}^{+}\right]^{2}\right.}{\left[\mathrm{H}^{+}\right]^{4}[\mathrm{Pu}(\mathrm{III})]^{2}\left(\mathrm{~K}_{\mathrm{d}}+\left[\mathrm{NO}_{3}\right]\right)^{2}}
$$


where $K^{\prime}$ is the reaction constant, and $K_{d}$ is the dissociation constant for $\mathrm{Pu}\left(\mathrm{NO}_{3}\right)^{+3}$. This rate dependance on acidity is of major significance because it indicated HAN's effectiveness could be sharply improved by reducing aqueous acidity in the $1 \mathrm{~B}$ mixersettler. At that time the aqueous acidity was 2.0 to $2.2 \mathrm{M}$ in about six stages (Figure 4 ).

The reduction rate of ferric to ferrous ion by HAN at different $\mathrm{HNO}_{3}$ concentrations was measured for conditions pertinent to our process as shown in Figure 5. Ferric nitrate, $\mathrm{HAN}$, and $\mathrm{HNO}_{3}$ were mixed to make solutions of $0.22 \mathrm{M}$ iron, $0.35 \mathrm{M}$ HAN (initial), and varying concentrations of $\mathrm{HNO}_{3}$. HAN concentration decreased as expected as $\mathrm{Fe}^{+2}$ molarity increased; otherwise HAN was stable. The data confirmed the reduction rate was faster at lower acidity and lower ferrous to ferric ratios. This data indicated that there would be some beneficial continuous replenishment of ferrous ion by HAN reduction of ferric ion in the $1 \mathrm{~B}$ mixer-settler. The rate of ferric ion reduction by $\mathrm{HAN}$ was subsequently studied by Bengtsson ${ }^{(6)}$. The effect of this reaction on the rate of $\mathrm{Pu}($ IV) reduction was found to be quite significant as shown in Figure 6 .

HAN stability at the temperature and acidities expected in the $1 B$ mixer-settler was verified. The mixer-settler operates with feed streams controlled at about $45^{\circ} \mathrm{C}$, and the aqueous residence time per stage is about 15 to 20 minutes. Therefore, data were needed to show HAN stability for longer than 2 hours at $40^{\circ} \mathrm{C}$ in acidities up to at least $2.2 \mathrm{~N} \quad \mathrm{HNO}_{3}$. Experiments conducted at $2.4-2.6 \mathrm{M} \mathrm{HNO}_{3}$ and $0.2 \mathrm{M} \mathrm{HAN}$ at $50^{\circ} \mathrm{C}$ produced autocatalytic decomposition of HAN after 62 hours; however at $40^{\circ} \mathrm{C}$, no decomposition was noted after 64 hours.

Plant use of HAN offered a potential hazard that had to be avoided; HAN fed to an evaporator in a low acid stream will concentrate along with the acid until the acidity is high enough to initiate the autocatalytic decomposition. If the HAN concentration prior to the time of its decomposition were high enough, this could cause pressurization of the evaporator and expel solution from the evaporator.

Laboratory experiments were conducted to determine the minimum nitric acid concentration at which HAN would rapidly (and therefore safely) decompose as it was being fed at low concentration to evaporators. The decomposition of HAN in different boiling $\mathrm{HNO}_{3}$ concentrations is shown in Figure 7. Solutions of nitric acid and HAN $(0.02$ and $0.05 \mathrm{M})$ were mixed; solutions were brought quickly to boiling, immediately cooled and analyzed. In every case, either all the HAN was still present or none was found. 1.0 molar nitric acid was found to be the concentration at which HAN decomposition occurs; therefore plant operating limits were set at $2.0 \mathrm{M}$ acid as a conservatively safe concentration for nitric acid in the evaporator to ensure rapid and safe decomposition of HAN as fed to the evaporators. 
The plutonium stream, $1 \mathrm{BP}$, from mixer-settler $1 \mathrm{~B}$ is subsequently treated with sodium nitrite to destroy residual ferrous sulfamate and oxidize plutonium to Pu(IV). Experiments were performed to determine conditions that would assure HAN destruction during this feed adjustment for the second plutonium cycle. Barney $(5)$ indicated that nitrous acid reacts mole for mole, with HAN,

$$
\mathrm{NH}_{2} \mathrm{OH}+\mathrm{HNO}_{2} \longrightarrow \mathrm{N}_{2} \mathrm{O}+2 \mathrm{H}_{2} \mathrm{O}
$$

and that the initial kinetics follows the equation

$$
\frac{-\mathrm{d}\left[\mathrm{HNO}_{2}\right]}{\mathrm{dt}}=\mathrm{k}\left[\mathrm{HNO}_{2}\right]\left[\mathrm{NH}_{3} \mathrm{OH}^{+}\right]\left[\mathrm{H}^{+}\right]
$$

Laboratory experiments indicated that a ratio of nitrous acid (or nitrite ion) to HAN of at least $3 / 1$ is needed to ensure HAN decomposition within 10 minutes. These results are consistent with earlier data by Swanson( 7$)$. Larger ratios, as shown in Figure 8 , are needed to ensure faster decomposition.

Miniature mixer-settler tests were performed during 1974-75, testing flowsheets containing HAN-FS in the $1 \mathrm{BX}$ stream. Results were encouraging, even though it was recognized that the miniature tests did not simulate plant conditions in several respects. These included radiolytic effects, residence times, and stage efficiencies. Figure 9 shows the results of one test run. The test data demonstrated that the plutonium distribution in the 16 stage $1 \mathrm{~B}$ mini-mixer-settler was normal at a $1 \mathrm{BX}$ concentration of $0.05 \mathrm{M}$ FS $0.10 \mathrm{M}$ HAN. This supported the conclusion that the addition of HAN would make it possible to reduce FS from the standard $1 B X$ concentration range then being used $(0.12$ to $0.14 \mathrm{M})$.

\section{Plant Testing Without Split-Scrub}

Several plant tests were made with mixtures of HAN and FS as the reductant for plutonium in the Purex first cycle $1 \mathrm{BX}$ stream (See Figure 2 Flowsheet) from 1978-1981. Actual operating time was about 15 months.

Good performance was demonstrated for a $1 B X$ concentration of $0.08 \mathrm{M}$ FS - $0.056 \mathrm{M} \mathrm{HAN}$ at a $1 \mathrm{AS} \mathrm{HNO}_{3}$ concentration of $3.0 \mathrm{M}$. First cycle operating performance was satisfactory and $1 B P$ product contained less than 100 parts uranium per million parts plutonium (ppm), which was the analytical limit of detection. The volume of neutralized low activity waste generated by FS was reduced by $33 \%$, compared to comparable pre-1978 operation. This is equivalent to a net waste reduction of 97 liters/metric ton uranium (MTU). Details of results are given in Table 1 . 
Under these conditions some plutonium refluxing was experienced as indicated by a buildup of plutonium inventory in the $1 \mathrm{~B}$ mixersettler as measured by neutron monitors. This happened when the $1 \mathrm{BX}-\mathrm{FS}$ concentration was lowered from $0.08 \mathrm{M}$ to $0.07 \mathrm{M}$ while using $3.0 \mathrm{M} \mathrm{HNO}_{3}$ in the $1 \mathrm{AS}$ stream. Samples of $1 \mathrm{BP}$ taken during reflux showed approximately $0.03 \mathrm{M}$ ferrous concentration compared to the 0.05 to $0.06 \mathrm{M}$ that would be expected under non-reflux conditions. The sulfamate concentration was only 0.02-0.03M. These data suggested that the sulfamate ion concentration, which acts as a "holding reductant" by reacting with nitrite ion, was too low at the lower FS concentration to provide adequate protection for the $\mathrm{HAN}-\mathrm{Fe}^{++}$reductant. Reflux occurred at $0.07 \mathrm{M}$ FS even when the $1 \mathrm{BX}-\mathrm{HAN}$ concentration was increased from 0.056 to $0.098 \mathrm{M}$. The mixer-settler plutonium inventory returned to normal within 4 hours after the $1 \mathrm{BX}-\mathrm{FS}$ concentration was raised to $0.14 \mathrm{M}$.

Nitric acid in the $1 \mathrm{~B}$ mixer-settler comes primarily (90\%) from the lAS stream by extracting into the solvent which produces the IAP stream. Since $\mathrm{HAN}$ reduced both $\mathrm{Pu}{ }^{+4}$ and ferric ions faster in low $\mathrm{HNO}_{3}$ concentrations, tests were conducted using a lower $1 \mathrm{AS} \mathrm{HNO}_{3}$ concentration of $2.2 \mathrm{M}$ to reduce the $1 \mathrm{~B}$ mixer-settler acid profile and increase the effectiveness of the HAN. This change allowed satisfactory operation at a $1 \mathrm{BX}$ concentration of $0.07 \mathrm{M}$ FS - $0.061 \mathrm{M}$ HAN which gave an additional waste volume reduction of 25 liters/MTU (Table 1). However, the 2.2M 1 AS acid also caused plutonium losses to the aqueous waste ( $1 \mathrm{AW}$ ) to increase by approximately a factor of two, from $0.25 \%$ to $0.45 \%$. Although this plutonium loss is subsequently recovered, it was decided to try an alternative method of lowering the $1 \mathrm{~B}$ mixer-settler acid profile to avoid this undesirable effect.

\section{Split-Scrub Flowsheet Development}

By using two scrub streams, a higher acid stream in stage 3 and a lower acid stream in stage 1 , two benefits were expected. It should be possible to maintain an acid profile high enough in the $1 \mathrm{~A}$ centrifugal contactor to keep plutonium losses low, while also reducing the acid in the $1 \mathrm{AP}$ solvent stream to achieve the desired lower acid profile in the $1 \mathrm{~B}$ mixer-settler.

The modified process was modeled using the SOLVEX (8) computer code to aid the determination of the optimum acid concentrations and flow ratios for the two scrub streams. The flowsheet selected and subsequently demonstrated in the plant is shown in Figure 10 . It uses a $0.08 \mathrm{M}$ nitric acid stream ( $1 \mathrm{AS}^{\prime}$ ) entering stage 1 , and a $3.0 \mathrm{M}$ nitric acid stream (1AS) entering stage 3. This gives a calculated reduction of the $1 \mathrm{AP}$ solvent acidity from $0.15 \mathrm{M}$ to $0.10 \mathrm{M}$ and the maximum stage acidity in the $1 \mathrm{~B}$ mixer-settler from about $2.0 \mathrm{M}$ to about $1.2 \mathrm{M}$ as shown in Figure 4 . 
The computer simulations indicated that decreasing the acidity in the 1AP, hence in the $1 \mathrm{~B}$ mixer-settler, would tend to give higher uranium contamination in the plutonium product stream (1BP). However, as shown in Figure 11 , the calculated increase in $\mathrm{U}$ content $(\mathrm{U} / \mathrm{Pu})$ was only a few parts per billion. It was recognized, however, that the quantitative reliability of the calculation was questionable even though the relative effects or trends were reliable.

The proposed split-scrub flowsheet was successfully demonstrated in 1981 in miniature mixer-settlers. Successful runs were made at $0.04 \mathrm{M} \mathrm{FS}-0.56 \mathrm{M} \mathrm{HAN}$ in the $1 \mathrm{BX}$ stream. This suggested that it might be possible to attain an additional $50 \%$ reduction in $\mathrm{FS}$ usage in the plant compared to the then current mixed reductant flowsheet (0.08M FS - 0.056M HAN), without compromising product quality.

A comparison of concentration profiles from computer simulation to those obtained from sampling during the miniature mixer-settler runs showed only minor variations. This can be seen in figures 12 , 13 , and 14 .

\section{Plant Testing of Split-Scrub HAN-PS Flowsheet}

Beginning in 1982, the split-scrub flowsheet was tested in the plant using mixtures of HAN-FS in the $1 \mathrm{BX}$, as shown in Figure 10. Initially, the FS concentration was set conservatively at $0.08 \mathrm{M}$, but was reduced stepwise. Good performance was demonstrated for a $1 \mathrm{BX}$ concentration of $0.04 \mathrm{M}$ FS $-0.056 \mathrm{M}$ HAN. First cycle operating performance was satisfactory and the plutonium in the $1 \mathrm{BP}$ product stream contained less than 100 ppm uranium.

This provided important confirmation that this lower acid profile in the $1 B$ mixer-settler still allowed acceptable $\mathrm{Pu} / \mathrm{U}$ partitioning. The $1 B P$ acidity was $1.0-1.1 \mathrm{M}$ compared to the $0.9 \mathrm{M}$ SOLVEX estimate and the $0.6 \mathrm{M}$ value predicted from the miniature mixer-settler testing. Some plant data indicate that if the $1 \mathrm{BP}$ acidity drops to 0.8 to 1.0 , the uranium contamination in the $1 \mathrm{BP}$ increases to about $200 \mathrm{ppm} \mathrm{U/Pu}$.

Operation at $0.04 \mathrm{M}$ FS reduces waste volume from the FS by 194 liters/MTU compared to operation at $0.12 \mathrm{M}$ FS (Table 1). At the present costs of chemicals and interim waste processing, this is equivalent to a net cost saving of $\$ 288,000 / 1000$ MTU processed. For permanent waste processing, it is about $\$ 10 \% / 1000 \mathrm{MTU}$.

Plutonium losses to the IAW stream leaving the 1ACC averaged about $0.10 \%$ while using the split-scrub flowsheet. Losses had typically been about $0.25 \%$ with the conventional flowsheet (these "losses" are subsequently recovered by anion exchange). The improvement is attributed to the higher $\mathrm{HNO}_{3}$ concentration profile in the extraction section of the 1ACC which the split-scrub makes possible. 
Fission product decontamination factors (DF) in the lACC were satisfactory. Limited data indicate zirconium-95 DF improved to about 1000 from 500-1200 ( 800 average) for the conventional flowsheet. The apparent improvement is attributed to the lower $\mathrm{HNO}_{3}$ concentration in stages 1 and 2 of the lACC.

This progran to reduce waste by the use of HAN is continuing, and it is hoped that the FS in the $1 B X$ stream can be reduced below the $0.04 \mathrm{M}$ concentration by further manipulation of $1 \mathrm{~B}$ bank acidity, HAN concentration, or temperature. 


\section{RERERENCES}

1. J. Malvyn McKibben and J. E. Bercaw, Hydroxylamine Nitrate as a Plutonium Reductant in the Purex Solvent Extraction Process, DP-1248, E. I. du Pont de Nemours \& Co., Savannah River Plant (January 1971).

2. A. A. Kishbaugh, Performance of a Multi-Stage Centrifugal Contactor DP-841, E. I. du Pont de Nemours \& Co., Savannah River Plant (October 1963).

3. D. A. Orth and J. M. McKibben, Evalution of Centrifugal Contactors, Transactions American Nuclear Society, meeting, Seattle, Washington, June 1959. DPSPU 69-30-1, E. I. du Pont de Nemours \& Co., Savannah River Plant, Aiken, S.C.

4. G. Scott Barney, "A Kinetic Study of the Reaction of Plutonium (IV) with Hydroxylamine," Journal of Inorganic and Nuclear Chemistry, Vol. 38, pp 1677-1681 (1976).

5. G. Scott Barney, The Reaction of Hydroxylamine with Nitrous Acid, ARH-SA-97, (June 1971).

6. Gosta Bengtsson, "A Kinetic Study of the Reaction Between Iron (III) and Hydroxylamine in Strongly Acidic Perchlorate Solutions," Acta Chemica Scandinavica, Vol 27, pp 1717-1724 (1973).

7. J. L. Swanson, Destruction of Nitrous Acid and Hydrazoic Acid in Purex Systems, BNWL-B-121 (August 1971).

8. W. C. Scotten, SOLVEX-A Computer Program for Simulation of Solvent Extraction Processes, DP-1391, E. I. du Pont de Nemours \& Co., Savannah River Plant (September 1975). 
TABLE 1

Summary of 1B Mixer-Settler Test Results

With Hydroxylamine Nitrate - Ferrous Sulfamate

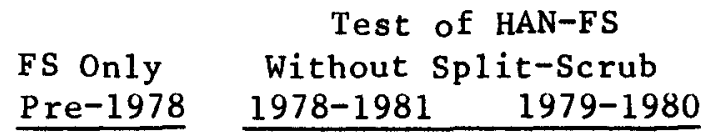

IAS' nitric acid, $M$

1AS nitric acid, ${ }^{\mathrm{a}} \mathrm{M}$

$1 B X$ or $1 B P$ volume,

L/MTU

IBX concentration, $\mathrm{b} M$ FS $\mathrm{SO}_{3} \mathrm{NH}_{2}^{-1}$ HAN

1BP concentration, $M$ $\mathrm{Fe}^{+2}$

$\mathrm{SO}_{3} \mathrm{NH}_{2}^{-1}$

HAN

Neutralized LAWC, $c$ L/MTU

Processing cost ${ }^{d}, \$ / M \Gamma U$

Waste storage

Cold Chemicals

Total Cost

Net Cost Saving, \$/MTU

\begin{tabular}{|c|c|c|c|c|c|}
\hline-1978 & $1978-1981$ & \multicolumn{2}{|c|}{$1979-1980$} & \multicolumn{2}{|c|}{1982} \\
\hline - & - & - & - & 0.08 & 0.08 \\
\hline 3.0 & 3.0 & 2.2 & 3.0 & 3.0 & 3.0 \\
\hline 1741 & 1741 & 1741 & 1741 & 1741 & 1741 \\
\hline 0.12 & 0.08 & 0.07 & 0.07 & 0.08 & 0.04 \\
\hline 0.25 & 0.17 & 0.15 & 0.15 & 0.17 & 0.09 \\
\hline-- & 0.056 & 0.049 & 0.098 & 0.056 & 0.056 \\
\hline 0.06 & 0.06 & 0.07 & $0.04^{e}$ & 0.07 & 0.03 \\
\hline 0.14 & 0.08 & 0.07 & 0.03 & 0.10 & 0.04 \\
\hline-- & 0.04 & 0.025 & 0.075 & 0.027 & 0.04 \\
\hline 291 & 194 & 170 & 170 & 194 & 97 \\
\hline 435 & 290 & 254 & 254 & 290 & 145 \\
\hline 99 & $\underline{130}$ & 115 & 173 & $\underline{130}$ & 101 \\
\hline 534 & 420 & 369 & 427 & 420 & 246 \\
\hline--- & 114 & 165 & 107 & 114 & 288 \\
\hline
\end{tabular}

Test of HAN-FS

With Split-Scrub 1982

a $3.0 \mathrm{M} \mathrm{HNO}_{3}$ gives a maximum acidity of $2.0 \mathrm{M}$ in the $1 \mathrm{~B}$ mixer-settler; split-scrub flowsheet gives maximum acidity of approximately $1.2 \mathrm{M}$ (Fig 4 ).

b Ferrous sulfamate (FS); sulfamate $\left(\mathrm{SO}_{3} \mathrm{NH}_{2}^{-1}\right)$ present as FS plus free sulfamic acid (0.01M); hydroxylamine nitrate (HAN). Concentrations are nominal flowsheet values.

c Low activity waste concentrate ( $28 \%$ solids) resulting from neutralizing $\mathrm{HNO}_{3}$; solids are also formed by reaction of FS with $\mathrm{NaNO}_{2}$.

d Interim storage cost based on $\$ 5.65 / \mathrm{gal}$ of waste shipped to Building $241-\mathrm{F}$. Cold chemical cost is $\$ 0.38 / 1 \mathrm{~b} 50 \% \mathrm{FS}$ and $\$ 0.51 / 1 \mathrm{~b} 16 \% \mathrm{HAN}$. All costs quoted for $10 / 81$.

e Test stopped due to plutonium reflux; 1BP analyses reflect samples taken during reflux. 


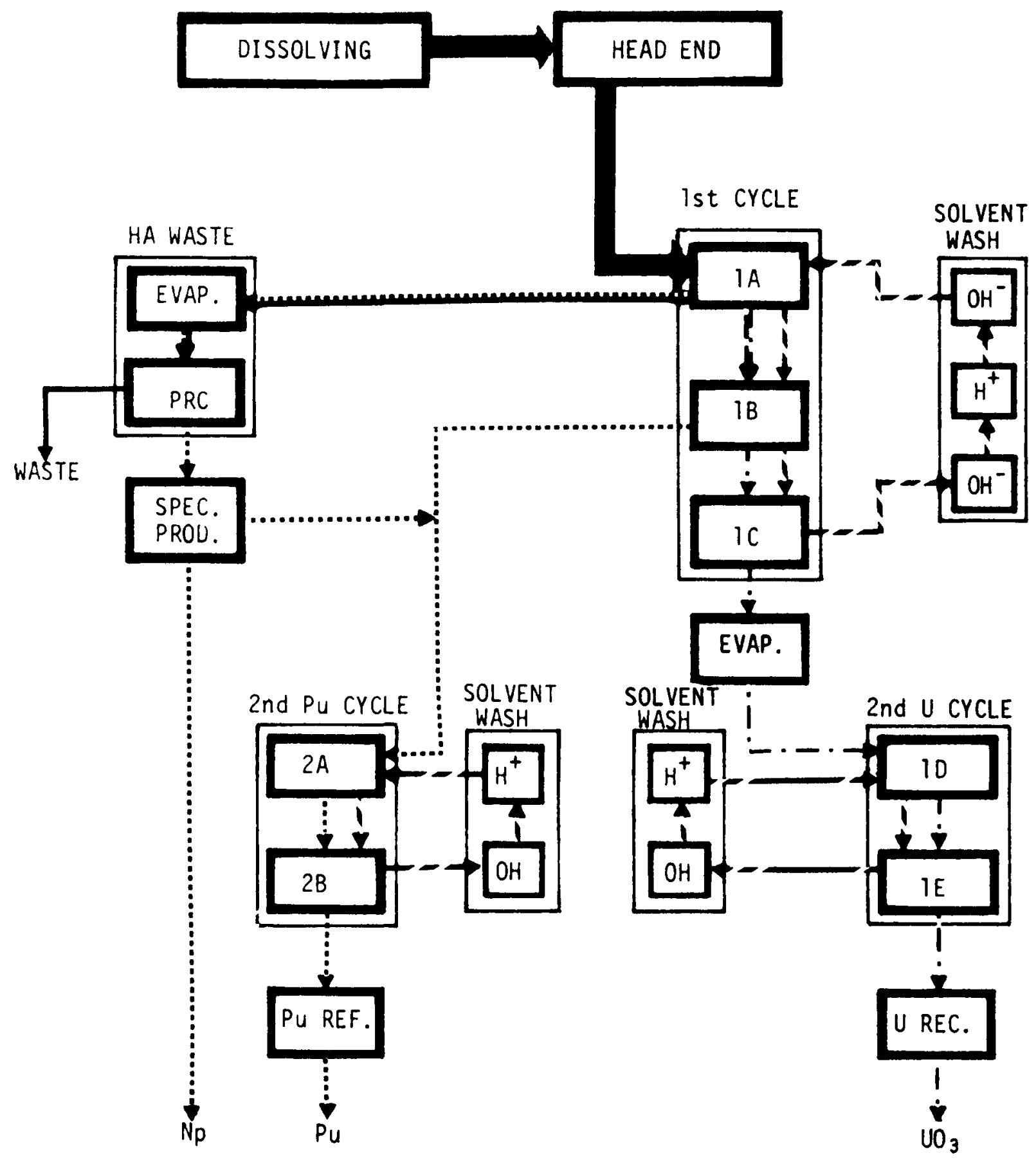

FIGURE 1. SRP Purex Process 


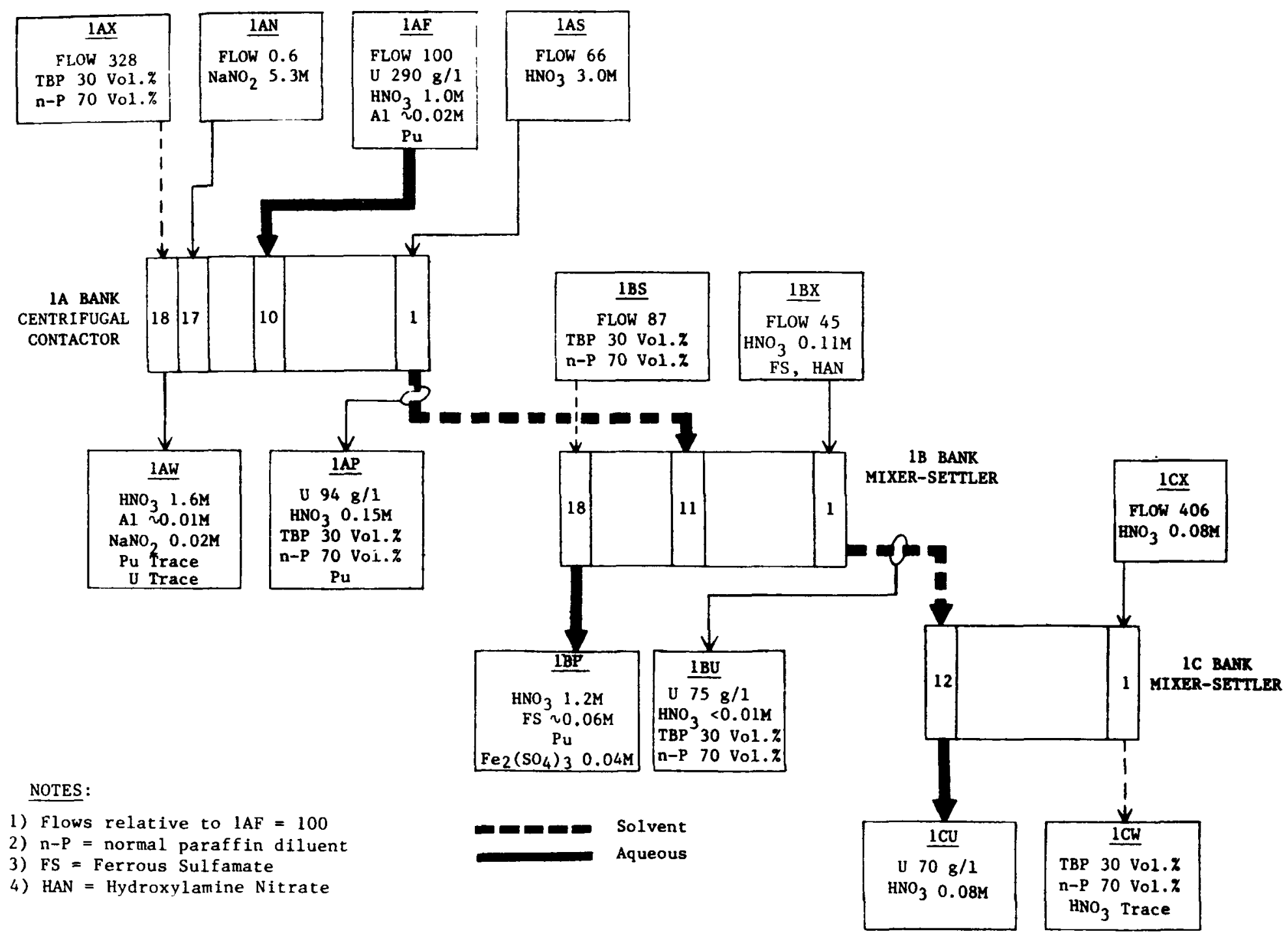

FIGURE 2. First Solvent Extraction Cycle, Standard Flowsheet (1954-1981) 


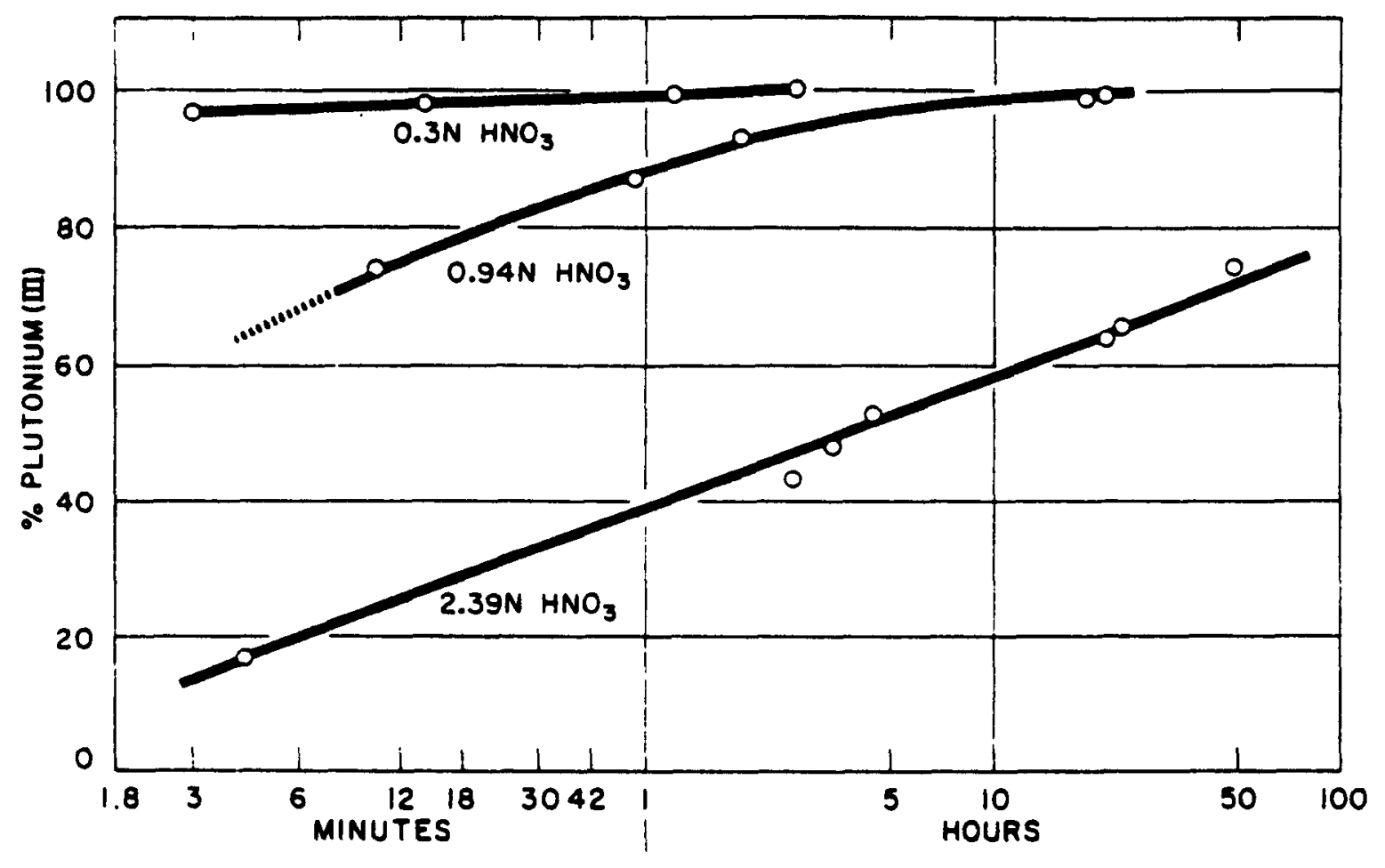

FIGURE 3. Effect of $\mathrm{HNO}_{3}$ on Rate of Hydroxylamine Nitrate Reduction of Pu(IV) 


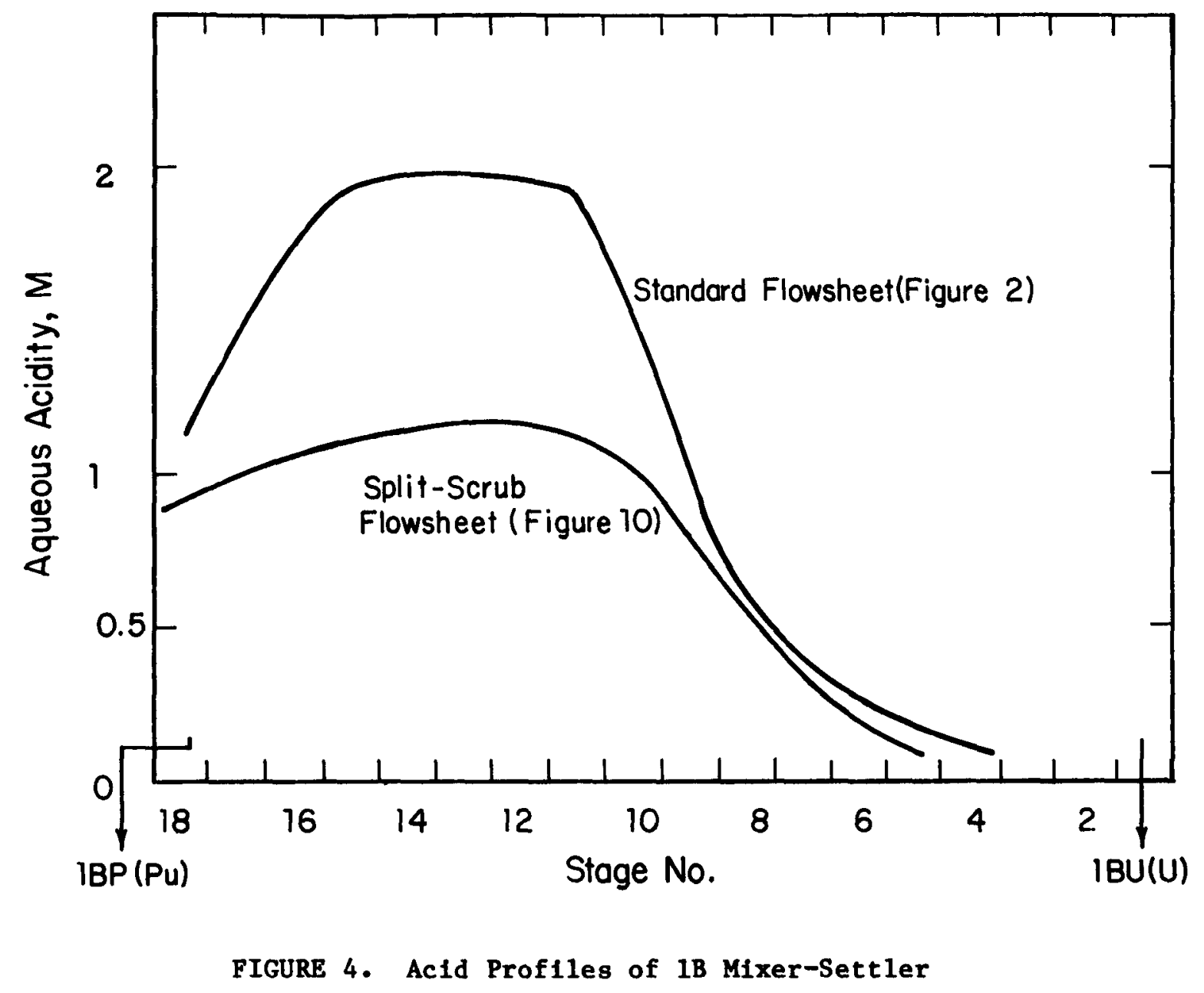




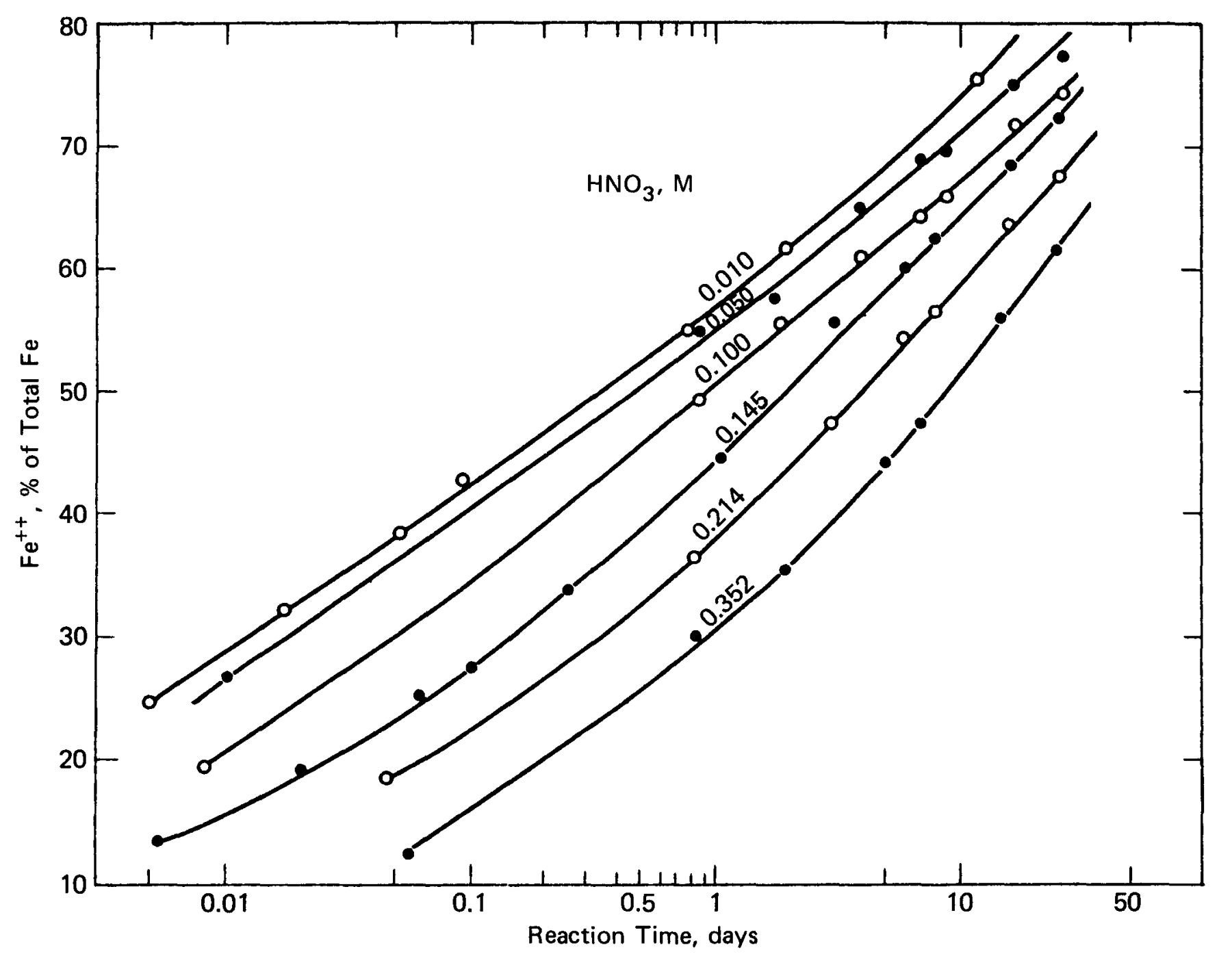

FIGURE 5. Rate of Ferric Reduction to Ferrous in $0.24-0.35 \mathrm{M}$ HAN at Various $\mathrm{HNO}_{3}$ Concentrations. Note: Total $\mathrm{Fe}=0.22 \mathrm{M}$. 


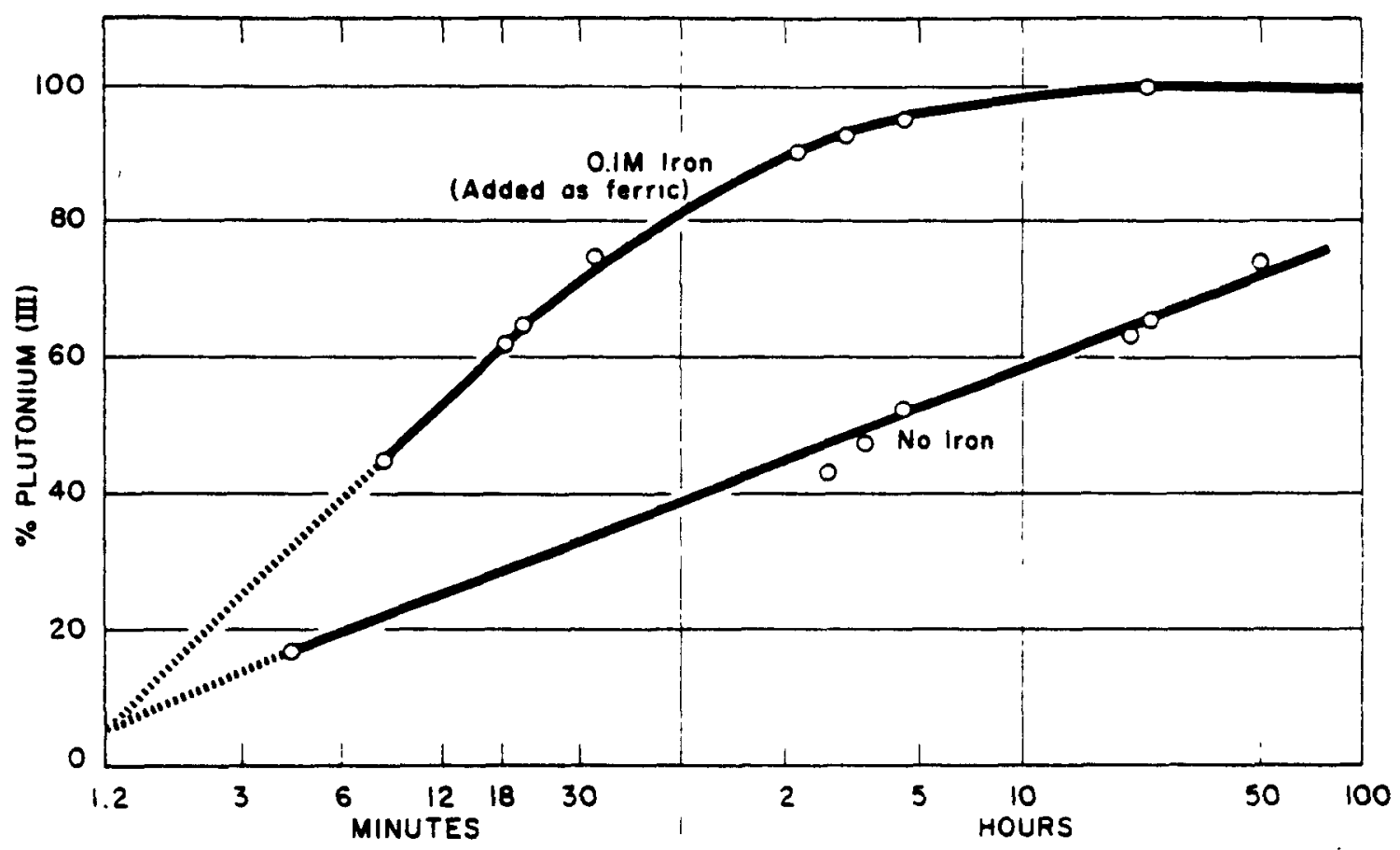

FIGURE 6. Effect of Iron on Rate of Pu(IV) Reduction by $0.1 \mathrm{~N}$ Hydroxylamine Nitrate at $2.4 \mathrm{~N} \mathrm{HNO}_{3}$ 


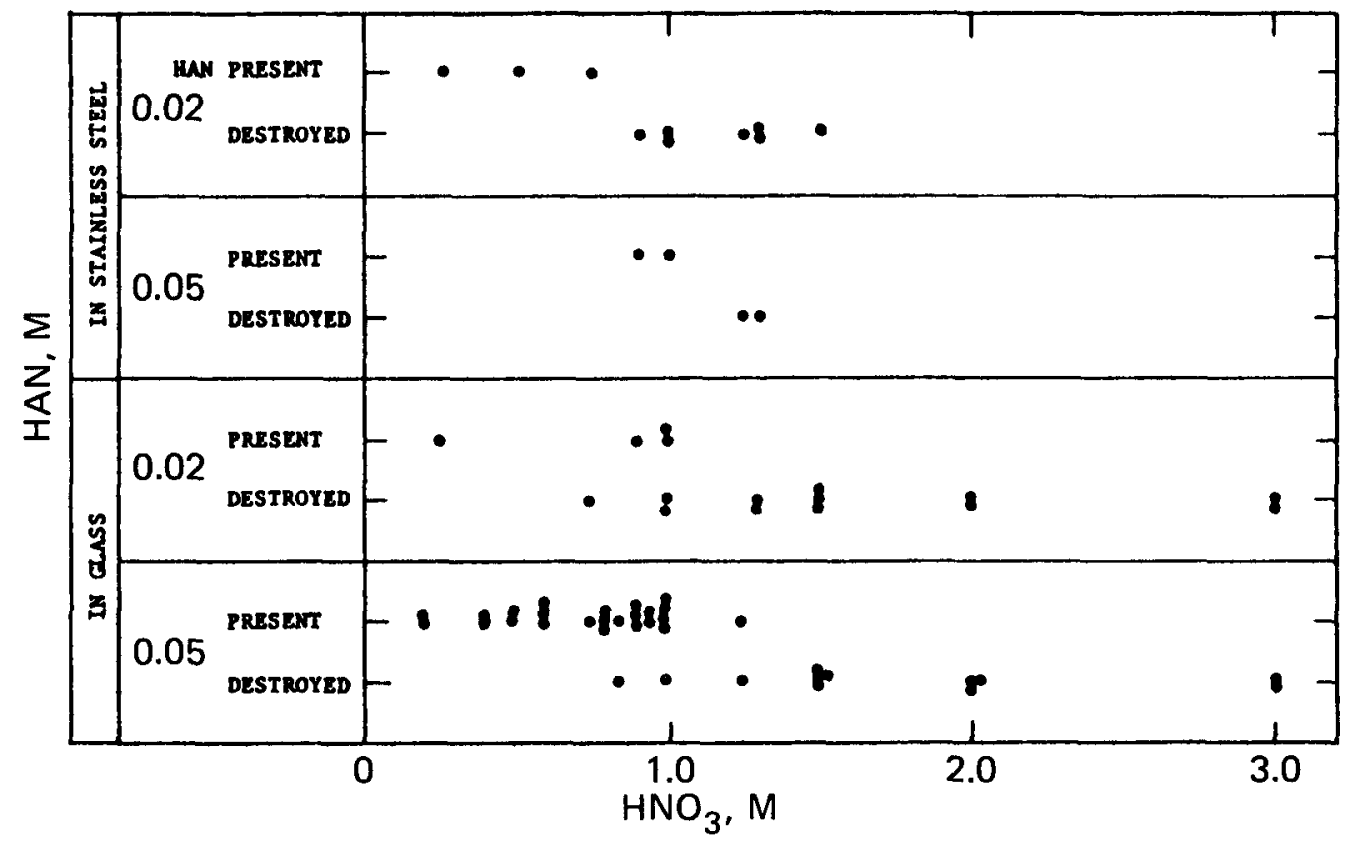

FIGURE 7. Nitric Acid Destruction of HAN.

Procedure: Solution mixed, brought to boil, removed from heat as soon as bolling began, cooled, analysed for HAN.

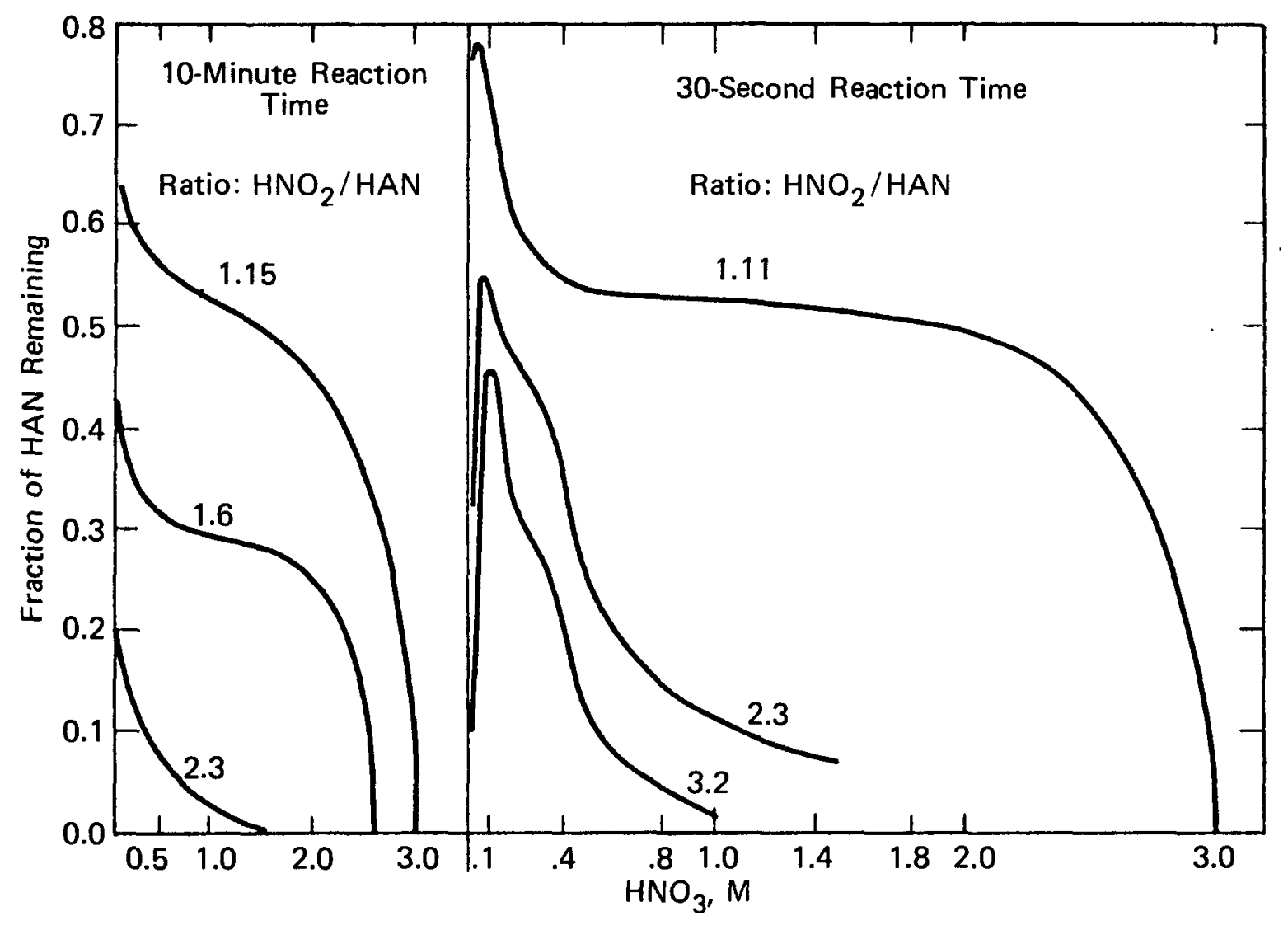

FIGURE 8. Nitrite Reaction With HAN 


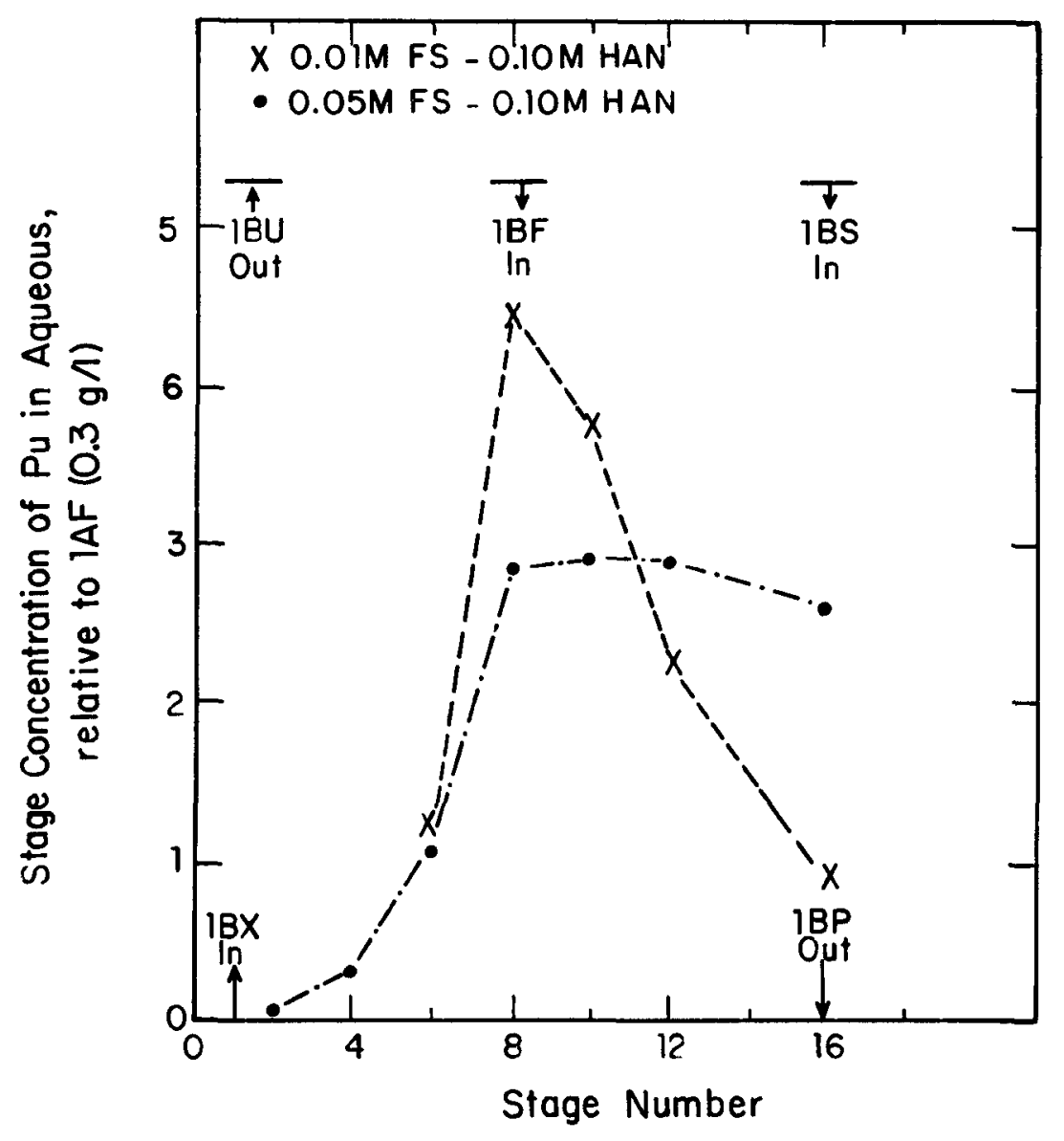

FIGURE 9. Aqueous Plutonium in Laboratory 1B Mixer-Settler 


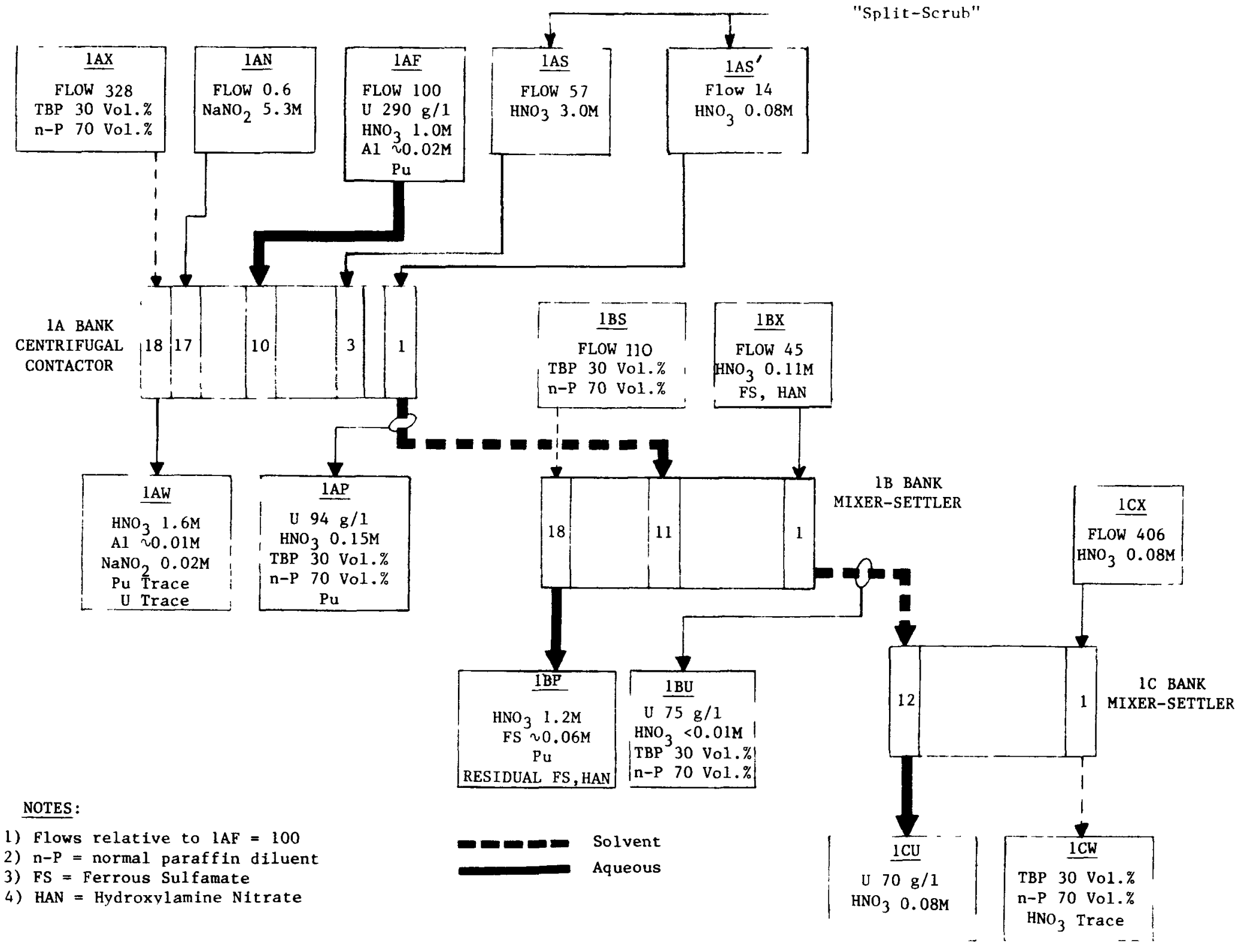

FIGURE 10. First Solvent Extraction Cycle, Split Scrub Flowsheet (1982) 


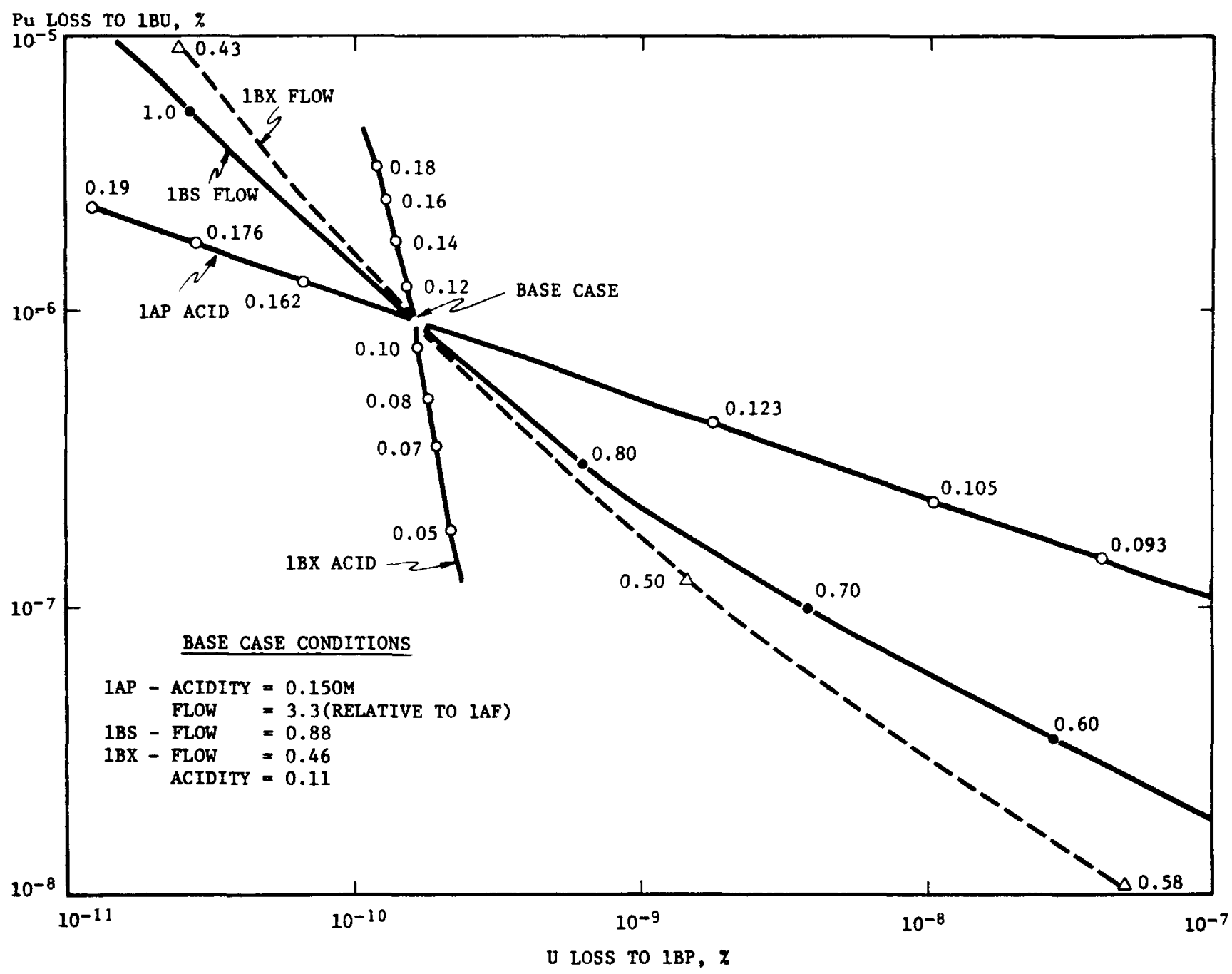

FIGURE 11. 1B Bank - Effect of Process Variables on Plutonium Loss to $1 \mathrm{BU}$ and Uranium Loss to $1 \mathrm{BP}$ 


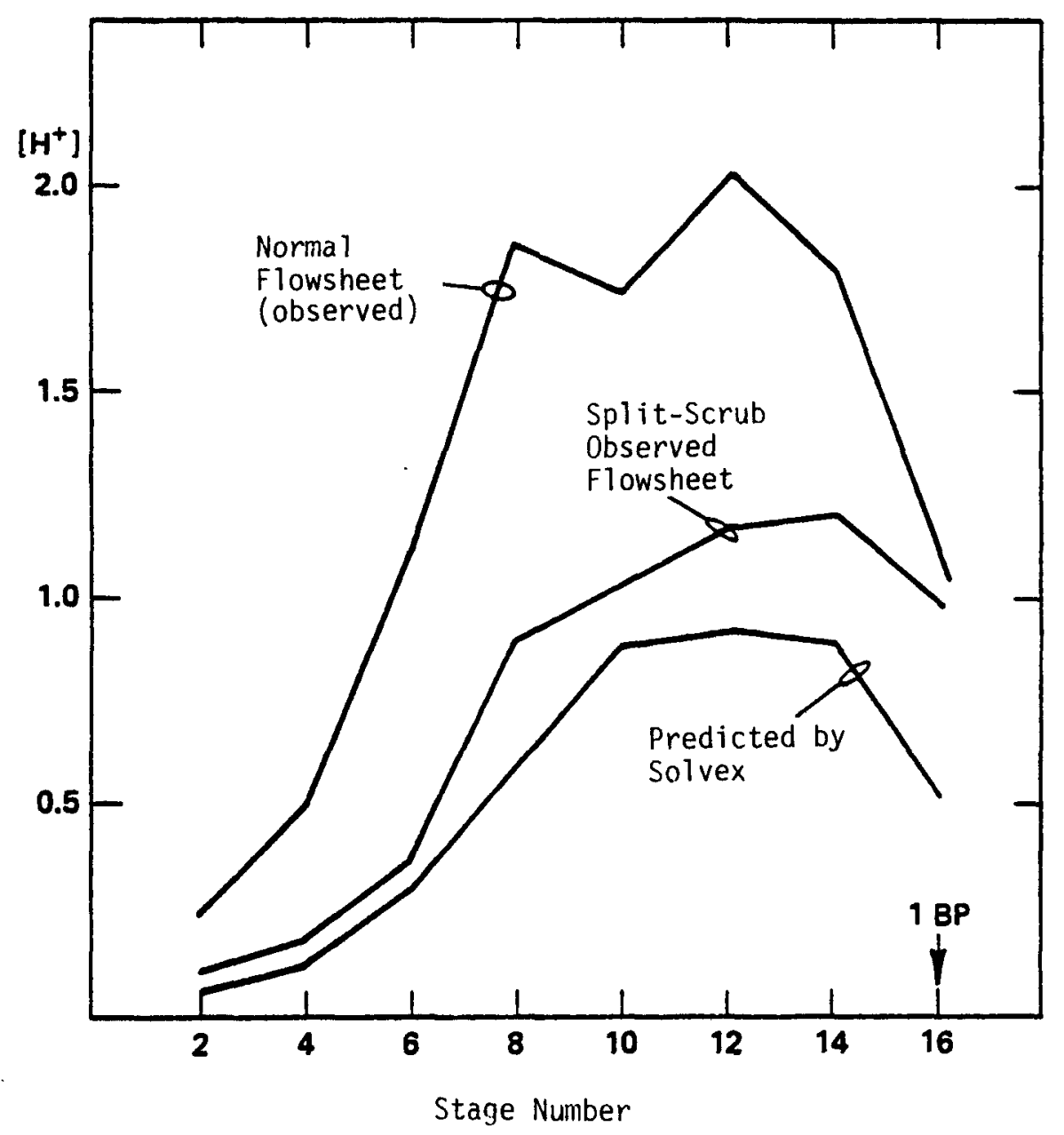

FIGURE 12. Aqueous Acidity Profiles, B-Bank From Miniature Mixer-Settler Runs 


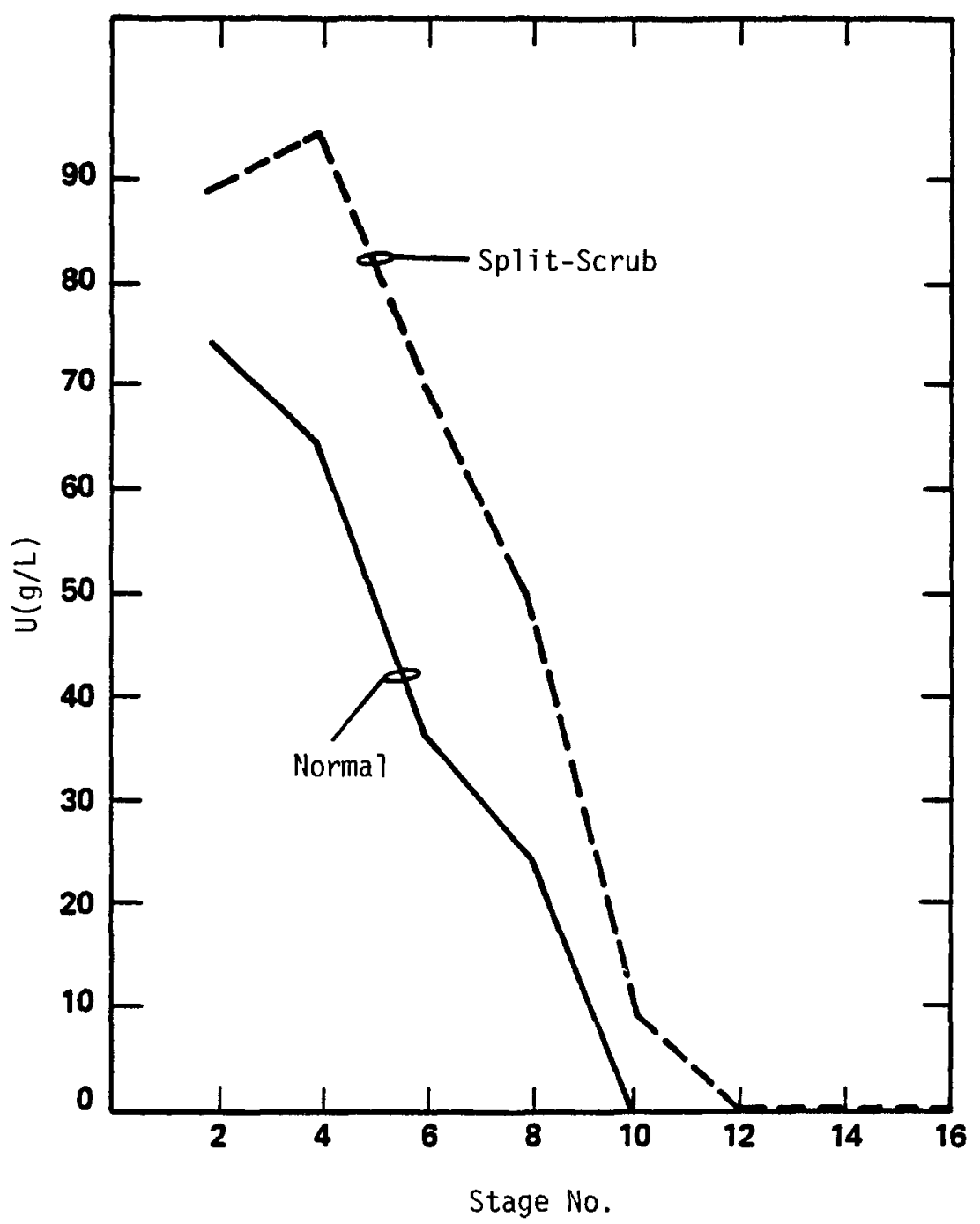

FIGURE 13. Aqueous Phase U Profiles Observed in Miniature Mixer-Settler Runs 


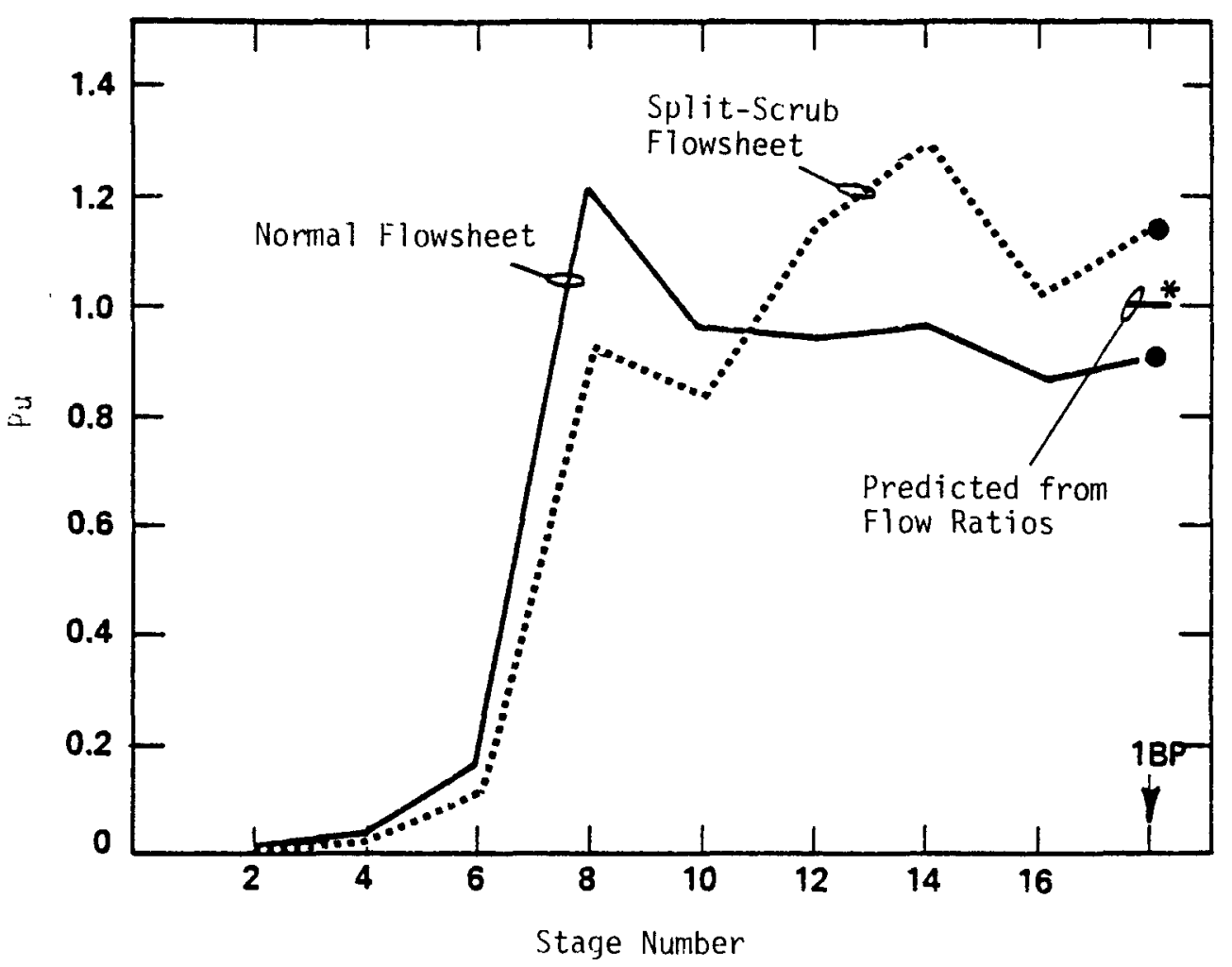

FIGURE 14. Aqueous Pu Profiles, B-Bank, From Miniature Mixer-Settler Runs 